\title{
Novel respiratory infectious diseases in Korea
}

\section{Hyun Jung Kim}

Division of Pulmonary and Critical Care Medicine, Department of Internal Medicine, Keimyung University Dongsan Hospital, Keimyung University School of Medicine, Daegu, Korea

Received: July 16, 2020

Revised: September 2, 2020

Accepted: September 6, 2020

Corresponding author:

Hyun Jung Kim

Division of Pulmonary and Critical

Care Medicine, Department of

Internal Medicine, Keimyung

University Dongsan Hospital,

Keimyung University School of

Medicine, 1095 Dalgubeol-daero,

Dalseo-gu, Daegu 42601, Korea

Tel: $+82-53-258-4988$

Fax: +82-53-258-4990

E-mail:khj82827@kmu.ac.kr
Respiratory infections are very common and highly contagious. Respiratory infectious diseases affect not only the person infected but also the family members and the society. As medical sciences advance, several diseases have been conquered; however, the impact of novel infectious diseases on the society is enormous. As the clinical presentation of respiratory infections is similar regardless of the pathogen, the causative agent is not distinguishable by symptoms alone. Moreover, it is difficult to develop a cure because of the various viral mutations. Various respiratory infectious diseases ranging from influenza, which threaten the health of mankind globally, to the coronavirus disease 2019, which resulted in a pandemic, exist. Contrary to human expectations that development in health care and improvement in hygiene will conquer infectious diseases, humankind's health and social systems are threatened by novel infectious diseases. Owing to the development of transport and trading activity, the rate of spread of new infectious diseases is increasing. As respiratory infections can threaten the members of the global community at any time, investigations on preventing the transmission of these diseases as well as development of effective antivirals and vaccines are of utmost importance and require a worldwide effort.

Keywords: Coronavirus infections; COVID-19; Human influenza; Middle East respiratory syndrome; SARS virus; Severe acute respiratory syndrome coronavirus 2

\section{Introduction}

As medical sciences advanced and sanitation improved, infectious diseases were perceived to occur in underdeveloped countries. However, an increase in the number of travelers and increased trading activity led to the influx of foreign infectious diseases and novel infectious diseases caused by varying strains. Respiratory viral infections are very common and highly contagious and can lead to big trends in a short time. As respiratory viral infections present similar signs and symptoms, the causative agent cannot be distinguished by clinical manifestations alone. Therefore, early diagnoses and proper establishment of infection control strategies are important. Respiratory infectious diseases affect not only an individual's health but also limit travel, paralyze the medical system, and affect the socialization and daily life of the affected patients and med- ical staff, thus hampering the social system.

Influenza, historically referred to as the Spanish flu, had infected 500 million people of the 1.6 billion people worldwide and 50 million people died. The mortality rate was approximately $10 \%$, and $3 \%$ of the world's population had succumbed to this disease [1]. From Spanish flu to severe acute respiratory syndrome (SARS) and Middle East respiratory syndrome (MERS) to coronavirus disease 2019 (COVID-19), which is currently a major problem globally, respiratory infections have had a huge impact on human health and healthcare systems; thus, a worldwide effort is required to combat this conundrum [2]. To implement future measures, we would like to summarize the respiratory infectious diseases that have recently affected human health and the society. Here, we review the current state of epidemiology, clinical manifestations, diagnosis, treatment, and prevention of novel respiratory infectious diseases. 


\section{Influenza}

\section{Introduction and epidemiology}

Globally, influenza is an important infectious disease, causing big and small epidemics annually [3]. Approximately $20 \%$ of the children and $5 \%$ of the adults suffer from influenza $A$ or $B$ worldwide each year [4]. The largest influenza pandemic was in 1918, when influenza A (H1N1), known as the "Spanish flu," resulted in 20 million deaths worldwide. Thereafter, there have been two major global outbreaks of influenza A: in 1957, influenza A (H2N2), namely, "Asian" influenza; and in 1967, influenza A (H3N2), namely, "Hong Kong" influenza [5]. The first case of swine-origin influenza A (H1N1) infection was reported in Mexico and the United States in April 2009, after which the novel influenza (H1N1) virus spread globally [6,7]. It mainly affected children and young adults and had no significant impact on the elderly. A similar pattern was also observed in Korea. The influenza A (H3N2) virus had the largest contribution to influenza-associated mortality in all age groups from 2009 to 2016; however, influenza A (H1N1) virus-associated influenza or pneumonia deaths were more common in those under 65 years old [8]. This is thought to be due to the cross-reactive effect of antibodies from past immunizations or infections to novel influenza A (H1N1) infections [6].

\section{Clinical manifestation and transmission}

Three mechanisms of person-to-person transmission have been identified, namely, small-particle aerosols, large droplets, and contact transmission [9]. The basic reproduction number (the mean number of secondary cases of infection transmitted by a single primary case in a susceptible population) is estimated to be approximately 1.3 to 1.7 but may rise up to 3.6 in crowded areas such as schools [7]. The clinical presentation of influenza ranges from afebrile upper respiratory illness to acute respiratory distress syndrome (ARDS) requiring mechanical ventilator support. Common symptoms of influenza include fever, chills, myalgia, cough, headache, etc. In 2009, a characteristic of the influenza H1N1 pandemic was to present as diffuse viral pneumonia associated with severe hypoxemia, ARDS, and shock in young adults. This phenomenon led to the promulgation of extracorporeal membrane oxygenation (ECMO) for ARDS treatment worldwide [10,11]. In Korea, mortality in intensive care units varied widely among hospitals, with the need for specialists of intensive care thus emerging [12].

\section{Diagnosis}

To confirm an influenza infection, real-time polymerase chain reaction (RT-PCR) or a viral culture is performed. As it takes about
3 days to culture the virus using rapid cell culture, RT-PCR with an upper airway specimen taking less than a day is widely used in clinical practice [13]. Detection using rapid antigen testing is fast; however, its sensitivity for $\mathrm{H} 1 \mathrm{~N} 1$ is low at 9.6\% to 51\% [14].

\section{Treatment}

Influenza is usually a self-limiting disease in a healthy person. Thus, while only supportive care is needed for healthy people, antiviral treatment is considered for high-risk patients including persons of any age hospitalized with influenza, children aged $<2$ years and adults aged $\geq 65$ years, outpatients at a high risk of complications from influenza, pregnant women and those within 2 weeks postpartum, etc. [15].

1) Neuraminidase inhibitors (oseltamivir and zanamivir) Antiviral treatment using neuraminidase inhibitors is recommended mainly for patients hospitalized with influenza H1N1 or for high-risk patients who are likely to develop complications from the seasonal influenza. It has been recognized as a prophylactic for influenza $A$ and $B$ in patients aged $>13$ years [9].

\section{2) Baloxavir marboxil}

Baloxavir marboxil (trade name Xofluza; Genentech Inc., San Francisco, CA, USA) is a selective inhibitor of the cap-dependent endonuclease. A significant reduction in viral load was observed a day after taking the drug compared with placebo or oseltamivir administration [16]. In addition, a single oral dose of baloxavir marboxil had a similar effect as oseltamivir in relieving influenza symptoms in high-risk outpatients and children $[17,18]$.

\section{Prevention}

Vaccination is the most effective way of preventing influenza and controlling the disease [19]. Oseltamivir, zanamivir, and baloxavir showed a high efficacy for postexposure prophylaxis in their contacts [20-22]. Influenza vaccinations are updated annually based on the annual surveillance data World Health Organization (WHO) to predict the influenza strain that will be prevalent next year [9]. The effect of vaccination is maximized in high-risk groups such as young children, immunocompromised patients, and adults aged 65 years and older [23]. Compliance with contact precaution and isolation guidelines is required to prevent person-to-person spread.

\section{Severe acute respiratory syndrome}

\section{Introduction and epidemiology}

SARS, a new coronavirus that causes severe viral pneumonia, was 
first reported in November 2002, in Guangdong, a province in southern China [24,25]. This new coronavirus variant was termed SARS coronavirus (SARS-CoV) $[25,26]$. The intermediate host of SARS-CoV was found to be a masked palm civet cat [27]. Researchers have found a virus genetically similar to this strain of coronavirus in masked palm civets sold in the animal market of Guangdong Province. Numerous studies have shown large number of SARS-related coronaviruses circulating in China's horseshoe bats, suggesting that the deadly strain probably originated in bats and, subsequently, transmitted the virus to civets before infecting humans [28]. SARS resulted in 8,273 cases in a year and 774 deaths with a fatality rate of $9.5 \%$ in 2002 . The national surveillance system for SARS was implemented on March 16, 2003, in Korea, and there were three probable cases of SARS diagnosed with clinical, laboratory, and radiological features. No patient was confirmed serologically in Korea, and all three probable cases were imported and showed improvement after provision of supportive care [29]. Both SARS and MERS are caused by coronaviruses; however, SARS propagated more in humans and had a relatively low mortality rate [30]. SARS appeared in 2002 and disappeared in the summer of 2003.

\section{Clinical manifestation and transmission}

Most patients ( $85 \%$ to $99 \%$ ) with SARS initially complained of fever and chills. Other symptoms included nonproductive cough (69\%), myalgia (49\%), and dyspnea (42\%) [31,32]. Initially, chest examination results were usually normal, but as the disease progressed, signs of consolidation, crackles, and dullness were observed [33]. Blood tests showed lymphopenia and elevated transaminase, lactate dehydrogenase, and creatinine kinase levels [34]. The radiographic findings of SARS are similar to pneumonia caused by other causes; they show airspace consolidation, mainly invading the peripheral and lower zone of the lungs. However, cavitation, hilar lymphadenopathy, and pleural effusion are rare [35].

SARS-CoV spreads quickly by close contact through droplet transmission or fomites. The highly infectious nature of the this viral disease is well illustrated by the fact that 158 patients were hospitalized with SARS in 2 weeks owing to their exposure to one patient in a general ward in Hong Kong [36].

\section{Diagnosis}

As molecular assays currently available for the detection of SARS$\mathrm{CoV}$ have low sensitivity and specificity during the early stages of the illness, additional serological tests indicating a significant increase in specific antibody titers or a positive viral culture is necessary to diagnose SARS $[37,38]$. This diagnostic process is usually based on the careful review of the clinical manifestations and epi- demiological and radiological findings.

\section{Treatment}

Antiviral treatments such as interferons, ribavirin, and lopinavir/ritonavir have been used in many patients; however, there is no clear conclusion regarding the effectiveness of these treatments [39].

\section{Prevention}

In the hospitals in Hong Kong, when 254 medical staff members who had contacted 11 index patients were divided into infected and noninfected groups and a survey was conducted about the use of masks, gloves, and gowns and hand washing while caring for the index patients with SARS, the infection rate was high in those who omitted at least one measure. Adopting precautionary measures to prevent droplet and contact transmission is of utmost importance [40].

\section{Middle East respiratory syndrome}

\section{Introduction and epidemiology}

A decade after SARS appeared, a new coronavirus causing severe viral pneumonia was reported in the Arabian Peninsula [41]. The clinical manifestations of MERS, caused by $\beta$-coronavirus of the $C$ lineage (MERS-CoV), can range from no symptoms to respiratory failure. During the first outbreak of MERS-CoV in June 2012 in Saudi Arabia, 688 people were confirmed to be infected, with a fatality rate of $35.7 \%$, i.e., 282 deaths in 27 countries [42]. In Korea, the large outbreak of MERS was mainly related to in-hospital infections. A total of 186 patients had been diagnosed with MERS-CoV in Korea, with 36 deaths [43]. MERS has a weaker human-to-human transmission than SARS; however, it has a higher mortality rate. The zoonotic vector and possible reservoir of MERS-CoV have been found to be dromedary camels, with bats as another possible vector for transmission to humans [44].

\section{Clinical manifestation and transmission}

Approximately $90 \%$ of patients with MERS complain of dyspnea, and $83 \%$ of patients show the symptom of coughing $[45,46]$. Fever and upper respiratory symptoms such as cough present first, followed by shortness of breath and lymphopenia 1 week later [46]. Serious complications usually occur in those with comorbidities such as diabetes, renal failure, and underlying immunosuppression. However, in patients without comorbidities, the infection may be asymptomatic or may show mild symptoms.

Imaging findings include nonspecific chest radiographs and ground-glass opacities in early chest tomographic scans followed by interlobular septal and intralobular interstitial thickening with 
peripheral and lower lobe involvement $[47,48]$.

Primary cases were found to show various mild to severe clinical symptoms after direct or indirect patient contact with dromedary camels. Secondary cases were due to human-to-human transmission via close contact and occurred among people with laboratory-confirmed MERS-CoV in household settings [42,49]. Contact and droplet transmission is suggested; however, the possibility of airborne or fomite transmission cannot be ruled out.

\section{Diagnosis}

MERS-CoV testing is performed by skilled technicians in appropriately equipped biosafety laboratories following the relevant technical and safety procedures [50]. MERS-CoV could be detected in a short time using a reverse transcription loop-mediated isothermal amplification technique and a vertical flow visualization strip assay [51]. Several serological assays, including enzyme-linked immunosorbent assay, recombinant spike immunofluorescent assay, and spike pseudoparticle neutralization and microneutralization assay, are available for the detection of MERS$\mathrm{CoV}[52]$.

\section{Treatment}

Although the role of antiviral treatment in MERS has not been clearly established, considering the high mortality rate, antiviral treatment could be considered in addition to supportive care in the patients with an older age, underlying diseases, breathing difficulties, and bilateral pneumonia [53]. Empirical treatments with convalescent plasma, interferon with or without ribavirin, and lopinavir/ritonavir have been studied in severely ill patients and are most likely to be beneficial, but evidence is weak and controlled trials are warranted $[44,54]$.

\section{Prevention}

MERS-CoV transmission in healthcare facilities mainly results from lapses in infection control measures and late isolation of suggested cases. Although currently, no human vaccine is available, the use of personnel protective equipment, early identification and isolation of patients, disinfection of environmental surfaces, and sanitization are required to minimize transmission [55].

\section{Coronavirus disease 2019}

\section{Introduction and epidemiology}

SARS-CoV-2 spread beyond China to the world within a few months. The COVID-19 outbreak that emerged in China in December 2019 spread globally, and in January 2020, the WHO declared that COVID-19 is an important issue threatening human health worldwide. SARS-CoV-2 is closely related to two bat-derived SARS-like (SL) coronaviruses: bat-SL-CoVAC45 and batSL-CoVZXC21 $[56,57]$. Current evidence indicates that SARS$\mathrm{CoV}-2$ spread to humans via transmission from wild animals illegally sold in Huanan's seafood wholesale market. Phylogenetic analysis shows that SARS-CoV-2 is a new member of the Coronaviridae family but is distinct from SARS-CoV (identity of approximately 79\%) and MERS-CoV (identity of approximately 50\%) [58]. Clinical characteristics comparing SARS, MERS and COVID-19 are seen in Table 1.

As of July 15, 2020, Korea reported a total of 13,551 confirmed cases and 289 deaths. Globally, approximately 13 million confirmed cases and 570,000 death were reported by the WHO [59]. In Korea, sporadic infections continue owing to community spread and globalization.

Table 1. Clinical features of human coronavirus pneumonia

\begin{tabular}{lccc}
\hline Feature & SARS $[24,32,34]$ & MERS $[42,44,49]$ & COVID-19 [56,57,68] \\
\hline Year first recognized & 2002 & 2012 & 2019 \\
Causative virus & SARS-CoV & MERS-CoV & SARS-CoV-2 \\
Intermediate host & Palm civets & Dromedary camels & Pangolins \\
Nosocomial infection & Yes & Yes & Yes \\
Healthcare worker infection (\%) & 21.0 & 18.6 & 3.8 \\
Incubation period (day) & $2-11$ & $2-13$ & $3-6$ \\
Treatment & Supportive care & Supportive care & Supportive care \\
Vaccination & - & - & - \\
Total case (global) & 8,096 & 2,229 & $12,964,809+$ \\
Total death (global) & 774 & 791 & $570,288+$ \\
CFR (\%) & 9.6 & 34.4 & 3.5 \\
CFR with comorbidities (\%) & 46.0 & 60.0 & 73.3 \\
\hline
\end{tabular}

SARS, severe acute respiratory syndrome; MERS, Middle East respiratory syndrome; COVID-19, coronavirus disease 2019; CoV, coronavirus; CFR, casefatality rate. 


\section{Clinical manifestation and transmission}

SARS-CoV-2 is highly contagious; when compared with SARS and MERS, the fatality rate of MERS was higher than that of SARS and COVID-19; however, within a short time, COVID-19 affected a larger number of people worldwide than SARS and MERS [56]. Current evidence suggests that human-to-human transmission of SARS-CoV-2 is via droplets expelled from the infected individual when in close contact while talking, coughing, or sneezing [57]. However, transmission via aerosols outside a laboratory setting has inconclusive evidence $[60,61]$. One of the biggest hurdles encountered while preventing spread of the disease is that the infection can be spread by asymptomatic as well as presymptomatic carriers [62].

The mean incubation period of the virus is 2 to 14 days, and the basic reproduction number is estimated at 2.24 to 3.58 . The major clinical manifestations include cough, fever, chills, dyspnea, myalgia, diarrhea, confusion, and pneumonia. Extrapulmonary symptoms include myocarditis, loss of taste and smell, and venous thrombosis [63-66]. These coronavirus infections cause more severe diseases among older individuals and people with comorbid conditions [67]. In Korea, the mortality rate is $2.36 \%$, wherein it is $1 \%$ in individuals aged $<50$ years; however, it is higher in older individuals. Therefore, as a higher mortality rate has been reported in individuals aged $>65$ years and having underlying diseases, appropriate precautionary measures are warranted [68].

\section{Diagnosis}

The genomic sequence of SARS-CoV-2 was released immediately on public databases in January 2020 after the start of the outbreak in Wuhan, China [69]. In Korea, infections were confirmed on the basis of a positive result for SARS-CoV-2 viral RNA in an RT-PCR assay or by virus isolation, irrespective of the clinical manifestations [70]. With an exponentially increasing number of patients, drivethrough screening centers were introduced in Korea, considering patient and medical staff safety while obtaining samples, which required equipment that could perform large-scale testing in a short duration [71].

\section{Treatment}

A specific treatment modality has not been developed yet [69]. To date, early detection and quarantine are considered optimum to minimize the spread of the disease. There are several ongoing clinical trials for COVID-19 treatment.

\section{1) Remdesivir}

Remdesivir, a nucleotide analog prodrug that inhibits viral RNA polymerase, is administered intravenously. Previously, it has been tested against Ebola virus and two coronaviruses, SARS and MERS [72]. It was first administered to a patient with COVID-19 in the USA [73]. The preliminary data indicated that on comparing 521 patients with placebo and 538 patients with a 10-day remdesivir regimen, the time to recovery was shorter in the remdesivir group (11 days) than in the placebo group (15 days) [74]. For patients with pneumonia and hypoxemia $\left(\mathrm{SpO}_{2} \leq 94 \%\right)$ caused by SARS-CoV-2, therapeutic effects of the 5-day and 10-day remdesivir regimen were similar [75]. Further, the compassionate use of remdesivir in patients hospitalized for severe COVID-19 showed clinical improvement in $68 \%$ of the patients [76]. In Korea, remdesivir permitted to be used for COVID-19 from July 2020. It was administered to 10 patients, including a patient on mechanical ventilation, and all patients showed clinical and laboratory signs of improvement without serious adverse events [77]. Large-scale clinical trials to ensure the safety and effectiveness of remdesivir in the treatment of COVID-19 are warranted [78]. Remdesivir is the most promising COVID-19 treatment candidate so far.

\section{2) Chloroquine/hydroxychloroquine}

Chloroquine is used for the treatment of malaria, and it demonstrated potential broad-spectrum antiviral activities by inhibiting endosomal acidification required for virus-host cell fusion [79]. The result of a multinational registry analysis of the use of chloroquine/hydroxychloroquine with or without a macrolide for treatment of COVID-19 showed that chloroquine/hydroxychloroquine was associated with a decreased in-hospital survival and an increased risk of arrhythmia when used for the treatment of COVID-19 [80]. In contrast, studies have shown that early (within 5 days from diagnosis) use of hydroxychloroquine inhibits SARS-CoV-2 shedding [81]. The role of hydroxychloroquine in the treatment and prophylaxis of COVID-19 is inconclusive.

\section{3) Lopinavir/ritonavir}

Lopinavir/ritonavir is a combination of human immunodeficiency virus protease inhibitors, with a modest antiviral activity against SARS-CoV-2 and nucleoside analogs, which increase drug bioavailability. Some studies have reported lopinavir/ritonavir to be a more effective agent for rapid viral clearance than hydroxychloroquine in mild to moderate cases of COVID-19 [82-84]. In contrast, some studies have reported that lopinavir/ritonavir did not shorten the duration of SARS-CoV-2 shedding in the patients with COVID-19 and a meta-analysis concluded that treatment with lopinavir/ritonavir had no significant benefits in reducing mortality and ARDS rates in patients with COVID-19 $[85,86]$. To date, available evidence regarding the efficacy of lopinavir/ritonavir in COVID-19 is weak. Since there is a lack of approved treatments for 
COVID-19, clinicians should not abandon the use of lopinavir/ritonavir as the results or ongoing clinical trials are pending.

\section{4) Convalescent plasma}

Convalescent plasma has been used in patients with SARS whose conditions continued to deteriorate, and several studies reported a shorter hospital stay and lower mortality in patients treated with convalescent plasma than in those not treated with convalescent plasma [87-89]. There are several cases reported about critically ill patients who received convalescent plasma and recovered from SARS-CoV-2 infections $[90,91]$. These results indicate that convalescent plasma might serve as a potential therapeutic for critically ill patients infected with SARS-CoV-2.

\section{5) Miscellaneous}

In subgroups of patients with severe COVID-19 with a possible cytokine storm syndrome, some immunomodulating treatments including steroids, intravenous immunoglobulins, interleukin (IL)1 blockers, and IL-6 receptor blockers are likely to be beneficial $[92,93]$. Anakinra (human IL-1 receptor antagonist) reduced the need for invasive mechanical ventilation and mortality among patients with severe forms of COVID-19 without serious side effects through randomized clinical trials [94].

\section{Prevention}

Vaccines are the most effective way to deal with infectious diseases. Three types of human coronaviruses (SARS-CoV, MERS-CoV, and SARS-CoV-2) have emerged over the past two decades, threatening the health of humankind; however, vaccinations against them are yet to be developed [2]. Several scientists and drug manufacturers worldwide are accelerating the development of COVID-19 vaccines $[95,96]$. Approximately 120 candidate molecules are under development for the vaccine, and several candidate SARS-CoV-2 vaccines are in phase 1 to 3 clinical trials. To date, for preventing the spread of SARS-CoV-2, the most effective methods are maintaining a physical distance of $\geq 1 \mathrm{~m}$, use of face masks and respirators, eye protection, and regular handwashing [97]. Globally, health authorities should take immediate action to prevent the spread of the pandemic and develop an effective vaccine.

\section{Conclusion}

So far, numerous respiratory infectious diseases have threatened humankind. Although treatments for influenza are constantly being developed, many people continue to succumb to the illness every year. There is no clear cure for the respiratory disease caused by the novel coronavirus. Therefore, tremendous efforts, such as extensive research on viruses and clinical diseases and development of new drugs and vaccines, are of essence. Concerns regarding the threat posed to the global health security by SARS-CoV-2 are escalating with an increasing number of outbreaks globally. With an estimated number of over 12 million cases worldwide, the COVID-19 pandemic could continue until the end of the year. Given that an outbreak is potentially a threat to every member of the global community, extensive efforts to prevent, detect, and respond to SARS$\mathrm{CoV}-2$ at the earliest is crucial. The COVID-19 pandemic is potentially the largest global health issue since the influenza pandemic in 1918. There are huge efforts being made to discover potential treatments for COVID-19. Clinical trials emphasize the need and the ability to obtain high-quality evidence even during the pandemic. Global cooperation and efforts are required to develop effective drugs and vaccines.

\section{Acknowledgments}

\section{Conflicts of interest}

No potential conflict of interest relevant to this article was reported.

\section{ORCID}

Hyun Jung Kim, https://orcid.org/0000-0002-1878-1111

\section{References}

1. Johnson NP, Mueller J. Updating the accounts: global mortality of the 1918-1920 "Spanish" influenza pandemic. Bull Hist Med 2002;76:105-15.

2. Guarner J. Three emerging coronaviruses in two decades. Am J Clin Pathol 2020;153:420-1.

3. Dowell SF, Ho MS. Seasonality of infectious diseases and severe acute respiratory syndrome-what we don't know can hurt us. Lancet Infect Dis 2004;4:704-8.

4. Nicholson KG, Wood JM, Zambon M. Influenza. Lancet 2003;362:1733-45.

5. Ghendon Y. Introduction to pandemic influenza through history. Eur J Epidemiol 1994;10:451-3.

6. Writing Committee of the WHO Consultation on Clinical Aspects of Pandemic (H1N1) 2009 Influenza; Bautista E, Chotpitayasunondh T, Gao Z, Harper SA, Shaw M, et al. Clinical aspects of pandemic 2009 influenza A (H1N1) virus infection. N Engl J Med 2010;362:1708-19.

7. Lessler J, Reich NG, Cummings DA; New York City Department of Health and Mental Hygiene Swine Influenza Investiga- 
tion Team. Outbreak of 2009 pandemic influenza A (H1N1) at a New York City school. N Engl J Med 2009;361:2628-36.

8. Hong K, Sohn S, Chun BC. Estimating influenza-associated mortality in Korea: the 2009-2016 seasons. J Prev Med Public Health 2019;52:308-15.

9. Paules C, Subbarao K. Influenza. Lancet 2017;390:697-708.

10. Zangrillo A, Biondi-Zoccai G, Landoni G, Frati G, Patroniti N, Pesenti A, et al. Extracorporeal membrane oxygenation (ECMO) in patients with $\mathrm{H} 1 \mathrm{~N} 1$ influenza infection: a systematic review and meta-analysis including 8 studies and 266 patients receiving ECMO. Crit Care 2013;17:R30.

11. Noah MA, Peek GJ, Finney SJ, Griffiths MJ, Harrison DA, Grieve R, et al. Referral to an extracorporeal membrane oxygenation center and mortality among patients with severe 2009 influenza A(H1N1). JAMA 2011;306:1659-68.

12. Cho J, Lee HJ, Hong SB, Suh GY, Park MS, Kim SC, et al. Structure of intensive care unit and clinical outcomes in critically ill patients with influenza A/H1N1 2009. Korean J Crit Care Med 2012;27:65-9.

13. Dwyer DE, Smith DW, Catton MG, Barr IG. Laboratory diagnosis of human seasonal and pandemic influenza virus infection. Med J Aust 2006;185:S48-53.

14. Peaper DR, Landry ML. Rapid diagnosis of influenza: state of the art. Clin Lab Med 2014;34:365-85.

15. Uyeki TM, Bernstein HH, Bradley JS, Englund JA, File TM, Fry $\mathrm{AM}$, et al. Clinical practice guidelines by the Infectious Diseases Society of America: 2018 update on diagnosis, treatment, chemoprophylaxis, and institutional outbreak management of seasonal influenzaa. Clin Infect Dis 2019;68:e1-47.

16. Hayden FG, Sugaya N, Hirotsu N, Lee N, de Jong MD, Hurt AC, et al. Baloxavir marboxil for uncomplicated influenza in adults and adolescents. N Engl J Med 2018;379:913-23.

17. Hirotsu N, Sakaguchi H, Sato C, Ishibashi T, Baba K, Omoto S, et al. Baloxavir marboxil in Japanese pediatric patients with influenza: safety and clinical and virologic outcomes. Clin Infect Dis 2020;71:971-81.

18. Ison MG, Portsmouth S, Yoshida Y, Shishido T, Mitchener M, Tsuchiya K, et al. Early treatment with baloxavir marboxil in high-risk adolescent and adult outpatients with uncomplicated influenza (CAPSTONE-2): a randomised, placebo-controlled, phase 3 trial. Lancet Infect Dis 2020;20:1204-14.

19. The Lancet. Preparing for seasonal influenza. Lancet 2018; 391:180.

20. Hayden FG, Belshe R, Villanueva C, Lanno R, Hughes C, Small I, et al. Management of influenza in households: a prospective, randomized comparison of oseltamivir treatment with or without postexposure prophylaxis. J Infect Dis 2004;189:440-9.
21. Hayden FG, Gubareva LV, Monto AS, Klein TC, Elliot MJ, Hammond JM, et al. Inhaled zanamivir for the prevention of influenza in families. Zanamivir Family Study Group. N Engl J Med 2000;343:1282-9.

22. Uyeki TM. Baloxavir for postexposure prophylaxis against influenza in households. N Engl J Med 2020;383:389-90.

23. Hak E, Hoes AW, Verheij TJ. Influenza vaccinations: who needs them and when? Drugs 2002;62:2413-20.

24. Peiris JS, Lai ST, Poon LL, Guan Y, Yam LY, Lim W, et al. Coronavirus as a possible cause of severe acute respiratory syndrome. Lancet 2003;361:1319-25.

25. Ksiazek TG, Erdman D, Goldsmith CS, Zaki SR, Peret T, Emery $\mathrm{S}$, et al. A novel coronavirus associated with severe acute respiratory syndrome. N Engl J Med 2003;348:1953-66.

26. Drosten C, Günther S, Preiser W, van der Werf S, Brodt HR, Becker S, et al. Identification of a novel coronavirus in patients with severe acute respiratory syndrome. N Engl J Med 2003; 348:1967-76.

27. Gu J, Korteweg C. Pathology and pathogenesis of severe acute respiratory syndrome. Am J Pathol 2007;170:1136-47.

28. Marra MA, Jones SJ, Astell CR, Holt RA, Brooks-Wilson A, Butterfield YS, et al. The genome sequence of the SARS-associated coronavirus. Science 2003;300:1399-404.

29. Lim S, Choi HS, Shin H, Ahn JH, BaikJJ, Choi YH, et al. Three cases of severe acute respiratory syndrome imported into South Korea. Korean J Med 2004;67:655-61.

30. de Wit E, van Doremalen N, Falzarano D, Munster VJ. SARS and MERS: recent insights into emerging coronaviruses. Nat Rev Microbiol 2016; 14:523-34.

31. Liu CL, Lu YT, Peng MJ, Chen PJ, Lin RL, Wu CL, et al. Clinical and laboratory features of severe acute respiratory syndrome vis-a-vis onset of fever. Chest 2004;126:509-17.

32. Cheng VC, Lau SK, Woo PC, Yuen KY. Severe acute respiratory syndrome coronavirus as an agent of emerging and reemerging infection. Clin Microbiol Rev 2007;20:660-94.

33. Tsang KW, Ho PL, Ooi GC, Yee WK, Wang T, Chan-Yeung M, et al. A cluster of cases of severe acute respiratory syndrome in Hong Kong. N Engl J Med 2003;348:1977-85.

34. Rota PA, Oberste MS, Monroe SS, Nix WA, Campagnoli R, Icenogle JP, et al. Characterization of a novel coronavirus associated with severe acute respiratory syndrome. Science 2003; 300:1394-9.

35. Wong KT, Antonio GE, Hui DS, Lee N, Yuen EH, Wu A, et al. Severe acute respiratory syndrome: radiographic appearances and pattern of progression in 138 patients. Radiology 2003; 228:401-6.

36. Lee N, Hui D, Wu A, Chan P, Cameron P, Joynt GM, et al. A 
major outbreak of severe acute respiratory syndrome in Hong Kong. N Engl J Med 2003;348:1986-94.

37. Hui DS, Wong PC, Wang C. SARS: clinical features and diagnosis. Respirology 2003;8(Suppl 1):S20-4.

38. Chan PK, To WK, Ng KC, Lam RK, Ng TK, Chan RC, et al. Laboratory diagnosis of SARS. Emerg Infect Dis 2004;10:82531.

39. Stockman LJ, Bellamy R, Garner P. SARS: systematic review of treatment effects. PLoS Med 2006;3:e343.

40. Seto WH, Tsang D, Yung RW, Ching TY, Ng TK, Ho M, et al. Effectiveness of precautions against droplets and contact in prevention of nosocomial transmission of severe acute respiratory syndrome (SARS). Lancet 2003;361:1519-20.

41. Zaki AM, van Boheemen S, Bestebroer TM, Osterhaus AD, Fouchier RA. Isolation of a novel coronavirus from a man with pneumonia in Saudi Arabia. N Engl J Med 2012;367:1814-20.

42. Hui DS, Azhar EI, Kim YJ, Memish ZA, Oh MD, Zumla A. Middle East respiratory syndrome coronavirus: risk factors and determinants of primary, household, and nosocomial transmission. Lancet Infect Dis 2018;18:e217-27.

43. Kim KH, Tandi TE, Choi JW, Moon JM, Kim MS. Middle East respiratory syndrome coronavirus (MERS-CoV) outbreak in South Korea, 2015: epidemiology, characteristics and public health implications. J Hosp Infect 2017;95:207-13.

44. Memish ZA, Perlman S, Van Kerkhove MD, Zumla A. Middle East respiratory syndrome. Lancet 2020;395:1063-77.

45. Assiri A, Al-TawfiqJA, Al-Rabeeah AA, Al-Rabiah FA, Al-Hajjar S, Al-Barrak A, et al. Epidemiological, demographic, and clinical characteristics of 47 cases of Middle East respiratory syndrome coronavirus disease from Saudi Arabia: a descriptive study. Lancet Infect Dis 2013;13:752-61.

46. Arabi YM, Arifi AA, Balkhy HH, Najm H, Aldawood AS, Ghabashi A, et al. Clinical course and outcomes of critically ill patients with Middle East respiratory syndrome coronavirus infection. Ann Intern Med 2014;160:389-97.

47. Choi WJ, Lee KN, Kang EJ, Lee H. Middle East respiratory syndrome-coronavirus infection: a case report of serial computed tomographic findings in a young male patient. Korean J Radiol 2016;17:166-70.

48. Ajlan AM, Ahyad RA, Jamjoom LG, Alharthy A, Madani TA. Middle East respiratory syndrome coronavirus (MERS-CoV) infection: chest CT findings. AJR Am J Roentgenol 2014; 203:782-7.

49. Elkholy AA, Grant R, Assiri A, Elhakim M, Malik MR, Van Kerkhove MD. MERS-CoV infection among healthcare workers and risk factors for death: retrospective analysis of all laboratory-confirmed cases reported to WHO from 2012 to 2 June
2018. J Infect Public Health 2020;13:418-22.

50. World Health Organization. Laboratory biorisk management for laboratories handling human specimens suspected or confirmed to contain influenza A (H1N1) causing the current international epidemics. Geneva: World Health Organization; 2009.

51. Huang P, Wang H, Cao Z, Jin H, Chi H, Zhao J, et al. A rapid and specific assay for the detection of MERS-CoV. Front Microbiol 2018;9:1101.

52. World Health Organization. Infection prevention and control during health care for probable or confirmed cases of Middle East respiratory syndrome coronavirus (MERS-CoV) infection: interim guidance [Internet]. Geneva: World Health Organization; 2019 [cited 2020 Jul 16]. https://www.who.int/csr/ disease/coronavirus_infections/ipc-mers-cov/en/.

53. Chong YP, Song JY, Seo YB, Choi JP, Shin HS; Rapid Response Team. Antiviral treatment guidelines for Middle East respiratory syndrome. Infect Chemother 2015;47:212-22.

54. Mo Y, Fisher D. A review of treatment modalities for Middle East Respiratory Syndrome. J Antimicrob Chemother 2016; 71:3340-50.

55. Baharoon S, Memish ZA. MERS-CoV as an emerging respiratory illness: a review of prevention methods. Travel Med Infect Dis 2019;32:101520.

56. Petrosillo N, Viceconte G, Ergonul O, Ippolito G, Petersen E. COVID-19, SARS and MERS: are they closely related? Clin Microbiol Infect 2020;26:729-34.

57. Jin Y, Yang H, Ji W, Wu W, Chen S, Zhang W, et al. Virology, epidemiology, pathogenesis, and control of COVID-19. Viruses 2020;12:372.

58. Rabaan AA, Al-Ahmed SH, Haque S, Sah R, Tiwari R, Malik YS, et al. SARS-CoV-2, SARS-CoV, and MERS-COV: a comparative overview. Infez Med 2020;28:174-84.

59. World Health Organization. Coronavirus disease (COVID-19): situation report, 176 [Internet]. Geneva: World Health Organization; 2020 [cited 2020 Jul 16]. https://apps.who.int/iris/handle/10665/333304.

60. Bourouiba L. Turbulent gas clouds and respiratory pathogen emissions: potential implications for reducing transmission of COVID-19. JAMA 2020;323:1837-8.

61. Lewis D. Is the coronavirus airborne? Experts can't agree. Nature 2020;580:175.

62. Rothe C, Schunk M, Sothmann P, Bretzel G, Froeschl G, Wallrauch C, et al. Transmission of 2019-nCoV infection from an asymptomatic contact in Germany. N Engl J Med 2020;382:9701.

63. Goyal P, Choi JJ, Pinheiro LC, Schenck EJ, Chen R, Jabri A, et 
al. Clinical characteristics of Covid-19 in New York City. N Engl J Med 2020;382:2372-4.

64. Baj J, Karakuła-Juchnowicz H, Teresiński G, Buszewicz G, Ciesielka M, Sitarz E, et al. COVID-19: specific and non-specific clinical manifestations and symptoms: the current state of knowledge.J Clin Med 2020;9:1753.

65. Lee Y, Min P, Lee S, Kim SW. Prevalence and duration of acute loss of smell or taste in COVID-19 patients. J Korean Med Sci 2020;35:e174.

66. Zhang Y, Xiao M, Zhang S, Xia P, Cao W, Jiang W, et al. Coagulopathy and antiphospholipid antibodies in patients with Covid-19. N Engl J Med 2020;382:e38.

67. Kim DW, Byeon KH, Kim J, Cho KD, Lee N. The correlation of comorbidities on the mortality in patients with COVID-19: an observational study based on the Korean National Health Insurance big data.J Korean Med Sci 2020;35:e243.

68. Wiersinga WJ, Rhodes A, Cheng AC, Peacock SJ, Prescott HC. Pathophysiology, transmission, diagnosis, and treatment of coronavirus disease 2019 (COVID-19): a review. JAMA 2020; 324:782-3.

69. Zhu N, Zhang D, Wang W, Li X, Yang B, Song J, et al. A novel coronavirus from patients with pneumonia in China, 2019. N EnglJ Med 2020;382:727-33.

70. Hong KH, Lee SW, Kim TS, Huh HJ, Lee J, Kim SY, et al. Guidelines for laboratory diagnosis of coronavirus disease 2019 (COVID-19) in Korea. Ann Lab Med 2020;40:351-60.

71. Kwon KT, Ko JH, Shin H, Sung M, Kim JY. Drive-through screening center for COVID-19: a safe and efficient screening system against massive community outbreak.J Korean Med Sci 2020;35:e123.

72. Mulangu S, Dodd LE, Davey RT Jr, Tshiani Mbaya O, Proschan M, Mukadi D, et al. A randomized, controlled trial of Ebola virus disease therapeutics. N Engl J Med 2019;381:2293-303.

73. Holshue ML, DeBolt C, Lindquist S, Lofy KH, Wiesman J, Bruce H, et al. First case of 2019 novel coronavirus in the United States. N Engl J Med 2020;382:929-36.

74. Beigel JH, Tomashek KM, Dodd LE, Mehta AK, Zingman BS, Kalil AC, et al. Remdesivir for the treatment of Covid-19-preliminary report. N Engl J Med 2020 May 22 [Epub]. https:// doi.org/10.1056/NEJMoa2007764.

75. Goldman JD, Lye DC, Hui DS, Marks KM, Bruno R, Montejano R, et al. Remdesivir for 5 or 10 days in patients with severe Covid-19. N Engl J Med 2020 May 27 [Epub]. https://doi.org/ 10.1056/NEJMoa2015301.

76. Grein J, Ohmagari N, Shin D, Diaz G, Asperges E, Castagna A, et al. Compassionate use of remdesivir for patients with severe Covid-19. N Engl J Med 2020;382:2327-36.
77. Lee C, Ahn MY, Byeon K, Choi JP, Hahm C, Kim H, et al. Clinical experience with use of remdesivir in the treatment of severe acute respiratory syndrome coronavirus 2 : a case series. Infect Chemother 2020;52:e46.

78. Norrie JD. Remdesivir for COVID-19: challenges of underpowered studies. Lancet 2020;395:1525-7.

79. Devaux CA, Rolain JM, Colson P, Raoult D. New insights on the antiviral effects of chloroquine against coronavirus: what to expect for COVID-19? Int J Antimicrob Agents 2020;55: 105938.

80. Cavalcanti AB, Zampieri FG, Rosa RG, Azevedo LC, Veiga VC, Avezum A, et al. Hydroxychloroquine with or without azithromycin in mild-to-moderate Covid-19. N Engl J Med 2020 Jul 23 [Epub]. https://doi.org/10.1056/NEJMoa2019014.

81. Hong KS, Jang JG, Hur J, Lee JH, Kim HN, Lee W, et al. Early hydroxychloroquine administration for rapid severe acute respiratory syndrome coronavirus 2 eradication. Infect Chemother 2020;52:e43.

82. Lim J, Jeon S, Shin HY, Kim MJ, Seong YM, Lee WJ, et al. Case of the index patient who caused tertiary transmission of COVID-19 infection in Korea: the application of lopinavir/ritonavir for the treatment of COVID-19 infected pneumonia monitored by quantitative RT-PCR. J Korean Med Sci 2020; 35:e79.

83. Kim JW, Kim EJ, Kwon HH, Jung CY, Kim KC, Choe JY, et al. Lopinavir-ritonavir versus hydroxychloroquine for viral clearance and clinical improvement in patients with mild to moderate coronavirus disease 2019. Korean J Intern Med 2020 Jun 16 [Epub].https://doi.org/10.3904/kjim.2020.224.

84. Cao B, Wang Y, Wen D, Liu W, Wang J, Fan G, et al. A trial of lopinavir-ritonavir in adults hospitalized with severe covid-19. N Engl J Med 2020;382:1787-99.

85. Zhang JJ, Lee KS, Ang LW, Leo YS, Young BE. Risk factors of severe dsease and efficacy of treatment in patients infected with COVID-19: a systematic review, meta-analysis and meta-regression analysis. Clin Infect Dis 2020 May 14 [Epub]. https:// doi.org/10.1093/cid/ciaa576.

86. Cheng CY, Lee YL, Chen CP, Lin YC, Liu CE, Liao CH, et al. Lopinavir/ritonavir did not shorten the duration of SARS CoV2 shedding in patients with mild pneumonia in Taiwan. J Microbiol Immunol Infect 2020;53:488-92.

87. Garraud O, Heshmati F, Pozzetto B, Lefrere F, Girot R, Saillol A, et al. Plasma therapy against infectious pathogens, as of yesterday, today and tomorrow. Transfus Clin Biol 2016;23:39-44.

88. Cheng Y, Wong R, Soo YO, Wong WS, Lee CK, Ng MH, et al. Use of convalescent plasma therapy in SARS patients in Hong Kong. Eur J Clin Microbiol Infect Dis 2005;24:44-6. 
89. Yeh KM, Chiueh TS, Siu LK, Lin JC, Chan PK, Peng MY, et al. Experience of using convalescent plasma for severe acute respiratory syndrome among healthcare workers in a Taiwan hospital. J Antimicrob Chemother 2005;56:919-22.

90. Bloch EM, Shoham S, Casadevall A, Sachais BS, Shaz B, Winters $\mathrm{JL}$, et al. Deployment of convalescent plasma for the prevention and treatment of COVID-19. J Clin Invest 2020;130:2757-65.

91. Li L, Zhang W, Hu Y, Tong X, Zheng S, Yang J, et al. Effect of convalescent plasma therapy on time to clinical improvement in patients with severe and life-threatening COVID-19: a randomized clinical trial. JAMA 2020;324:1-11.

92. Mehta P, McAuley DF, Brown M, Sanchez E, Tattersall RS, Manson JJ, et al. COVID-19: consider cytokine storm syndromes and immunosuppression. Lancet 2020;395:1033-4.

93. RECOVERY Collaborative Group; Horby P, Lim WS, Emberson JR, Mafham M, Bell JL, et al. Dexamethasone in hospital- ized patients with covid-19-preliminary report. N Engl J Med 2020 Jul 17 [Epub]. https://doi.org/10.1056/NEJMoa2021436.

94. Huet T, Beaussier H, Voisin O, Jouveshomme S, Dauriat G, Lazareth I, et al. Anakinra for severe forms of COVID-19: a cohort study. Lancet Rheumatol 2020;2:e393-400.

95. Thanh Le T, Andreadakis Z, Kumar A, Gómez Román R, Tollefsen S, Saville M, et al. The COVID-19 vaccine development landscape. Nat Rev Drug Discov 2020;19:305-6.

96. Lurie N, Saville M, Hatchett R, Halton J. Developing Covid-19 vaccines at pandemic speed. N Engl J Med 2020;382:1969-73.

97. Chu DK, Akl EA, Duda S, Solo K, Yaacoub S, Schünemann HJ, et al. Physical distancing, face masks, and eye protection to prevent person-to-person transmission of SARS-CoV-2 and COVID-19: a systematic review and meta-analysis. Lancet 2020;395:1973-87. 